Proceedings

\title{
Public Health Messages Associated with the Low Exposure Category of the UV Index Need Reconsideration ${ }^{+}$
}

\author{
Maria Lehmann ${ }^{1}$, Annette B. Pfahlberg ${ }^{1}$, Henner Sandmann ${ }^{2}$, Wolfgang Uter ${ }^{1}$ \\ and Olaf Gefeller ${ }^{1, *}$ \\ 1 Department of Medical Informatics, Biometry and Epidemiology, Friedrich-Alexander-Universität \\ Erlangen-Nürnberg (FAU), Waldstr. 6, 91054 Erlangen, Germany; maria.lehmann@fau.de (M.L.); \\ annette.pfahlberg@fau.de (A.B.P.); wolfgang.uter@fau.de (W.U.) \\ 2 uv-tech consulting, Tönniesstr. 9, 24106 Kiel, Germany; sandmann@uv-tech.de \\ * Correspondence: olaf.gefeller@fau.de; Tel.: +49-9131-85-22750 \\ + Presented at the 1st International Electronic Conference on Environmental Health Sciences, \\ 15 November-7 December 2018; Available online: https://iecehs-1.sciforum.net/.
}

Published: 14 November 2018

\begin{abstract}
Overexposure to ultraviolet (UV) radiation is the main modifiable risk factor for skin cancer. The Global Solar Ultraviolet Index (UVI) was introduced as a tool to visualize the intensity of UV radiation on a certain day which should enable and encourage people to take appropriate protective measures. The exposure category 'low' of the UVI, including values from 0 to 2, was linked to the health message 'No protection required' by the World Health Organization and collaborating centres. However, published evidence corroborating this advice is scarce. Therefore, we analysed ambient erythemal irradiance data of 14,431 daily UVI time series of low UVI days. Data were gathered at nine stations of the German solar UV monitoring network-covering all major climate areas in Germany - in the years 2007-2016. We compared ambient erythemal doses calculated for various time intervals with average minimal erythemal doses (MEDs) of the Caucasian Fitzpatrick skin phototypes I-IV to assess the potential for skin damage arising from sun exposure on days with low UVI values. The most common months for the occurrence of days with low UVI values in our dataset were January and December, February and November, and March and October for UVI 0, 1 and 2, respectively. Our results indicate that on days with a UVI value of 0 , risk of deterministic radiation injury (solar erythema) is negligible. Conversely, the above-mentioned health message appears misleading when melano-compromised individuals spend several hours outdoors on days with a UVI value of 2, as median doses exceed the MEDs of Fitzpatrick skin types I and II after an exposure duration of only $2 \mathrm{~h}$ around solar noon. Under very rare specific circumstances, MEDs of those two most sensitive skin types can also be exceeded even on days with UVI 1. Hence, two aspects of current public health messages may need reconsideration: on the one hand, the health message related to an 'innocuous level' of the UVI and, on the other hand, a possible adaption of UVI-related health messages to different skin types.
\end{abstract}

Keywords: Ultraviolet rays; health promotion; radiation monitoring; sun protection

\section{Introduction}

Ultraviolet (UV) radiation, approaching Earth every day in form of sunlight, has officially been classified as carcinogenic to humans by the International Agency for Research on Cancer [1]. Overexposure to UV radiation is responsible for a substantial proportion of melanoma and non-melanoma skin-cancers [2], whose incidence rates are increasing worldwide [3,4]. This implies 
that skin cancer is largely preventable using appropriate sun protection. To enable the population to choose such an appropriate level of sun protection, the World Health Organization (WHO) and collaborating centers introduced a Global Solar UV Index (UVI) in 1995 [5]. This index is a unitless quantity (reported as rounded to the nearest whole number), proportional to the daily maximum 30-min moving average of the intensity of erythemally weighted [6] solar UV irradiance (Eer) on the Earth's surface [7]. In a practical guide published in 2002 [7], five exposure categories linked to specific health messages were introduced. These messages are intended to be valid for various exposure durations and skin phototypes, but focus on fair skinned people [7]. The exposure category 'low', comprising UVI values from 0 to 2, is related to the simple messages 'No protection required' and 'You can safely stay outside!' No explanation on how the classification of the UVI scale into the different exposure categories was derived and how the adequacy of the linked health messages was validated has been given in any of the WHO documents. The aim of our study is thus to evaluate potential erythemal effects of exposure to solar UV radiation on days with low UVI values, especially considering the difference in susceptibility to UV radiation-induced damage between distinct skin phototypes. To this end, we analyze a large high-quality dataset of measurements of erythemal irradiance on days of the low exposure category to quantify ambient erythemal UV doses attained during these days in detail.

\section{Materials and Methods}

\subsection{Data Sources}

Measurements of diurnal courses of ambient Eer over the ten year period from 2007 until 2016, conducted by nine stations of the German solar UV monitoring network, covering all major regions of Germany [8,9], provide the basis for the study. At each station solar UV spectra were measured every 6 min each day between sunrise and sunset using spectroradiometers (DTM300 or DM150, Bentham, Reading, UK).

Criteria for technical quality were applied to the data, i.e., plausibility checks including wavelength and absolute accuracy checks of the spectroradiometer, and completeness of the data over the day. For each day, the UVI value was determined by using 30-min intervals without missing values for the calculation of the moving average. Note that, in our study, the term 'day' does not refer to a single specific calendar day, but is our unit of observation equivalent to the diurnal course of Eer during one calendar day at one specific station of the network. This makes it possible for one calendar day to be included in the dataset more than once if low UVI conditions were present concurrently at multiple stations of the network.

\subsection{Statistical Analysis}

To facilitate comparability between data from different stations and to compensate for annual variation of solar noon at each station, we transformed the time base of the data from Coordinated World Time to Local Solar Time (LST), where solar noon always occurs at 12:00. To analyze potential UV hazards on days with low UVI values, erythemal irradiance data were linearly interpolated and integrated over certain time intervals to calculate erythemal doses $\left(\mathrm{H}_{\mathrm{er}}\right)$ received therein. The considered intervals were 11:45-12:15, 11:30-12:30, 11:00-13:00, 10:30-13:30 and 10:00-14:00, corresponding to $0.5,1,2,3$ and $4 \mathrm{~h}$ around solar noon, respectively. Ambient erythemal doses were also calculated for the intervals 08:00-10:00, 14:00-16:00, 07:30-10:30 and 13:30-16:30, being equivalent to $2 \mathrm{~h}$ and $3 \mathrm{~h}$, each before and after noon, respectively.

Descriptive information on average erythemal doses is reported as median (p10, p90 percentile). We chose to report these robust measures instead of mean and standard deviation to account for skewness in the distribution of $\mathrm{H}_{\mathrm{er}}$ values. Doses are compared to average minimal erythemal doses (MEDs) of Fitzpatrick skin types [10] I through IV as shown in Table 1. One MED is the amount of (solar) UV exposure which produces minimal perceptible reddening of the skin (solar erythema) $24 \mathrm{~h}$ after exposure. Hence, one MED can be considered a short-time maximum dose that should not be exceeded to prevent detrimental effects of UV radiation on the human body [11]. 
Additionally, we report the percentages of days for which those MEDs are exceeded in the given time intervals. Data analysis was performed using the statistical software package $R$ (Version 3.4.1) [12].

Table 1. Characteristics of skin types according to Fitzpatrick [10] and corresponding minimal erythemal doses (MEDs) according to the International Commission on Non-Ionizing Radiation Protection [13] in terms of Standard Erythema doses (1 SED $=1$ Standard Erythema Dose $=100 \mathrm{~J} / \mathrm{m}^{2}$ weighted with the International Commission on Illumination (CIE) erythema reference action spectrum [6]).

\begin{tabular}{cccc}
\hline Skin Type & Tan & Burn & Minimal Erythemal Dose (SED) \\
\hline I & Never & Always & 2.0 \\
II & Sometimes & Sometimes & 2.5 \\
III & Always & Rarely & 4.0 \\
IV & Always & Never & 6.0 \\
\hline
\end{tabular}

\section{Results}

\subsection{Dataset Description}

Our final dataset consisted of erythemal irradiance data of 4,961 days with a UVI value of 0 ; 6,117 days with UVI 1 and 3,353 days with UVI 2. Most days with a UVI value of 0 occurred in December $(n=1,949 ; 39.3 \%)$, followed by January $(n=1,515 ; 30.5 \%)$ and November $(n=939 ; 18.9 \%)$. This unimodal distribution is due to the fact that the winter solstice with greatest solar zenith angle (SZA) is around December 21 on the Northern hemisphere. The majority of days with a UVI value of 1 occurred in February $(n=1,526 ; 24.9 \%)$, November $(n=1,281 ; 20.9 \%)$ and October $(1,047 ; 17.1 \%)$, giving a bimodal distribution. This type of distribution can also be found for the UVI 2 days which largely originate from March $(n=1,061 ; 31.6 \%)$ and October $(n=913,27.2 \%)$. The frequency of all low exposure UVI values is low in the spring and summer months, as these months provide only $0.4 \%$, $7.7 \%$ and $37.0 \%$ of days in the sample for UVI 0,1 and 2, respectively (with seasons defined astronomically [14], so usually March 21 till September 20).

\subsection{Comparison of Computed Erythemal Doses with MEDs}

Table 2 shows ambient erythemal doses received during fixed time intervals and the proportion of days for which one MED of skin types I to IV is exceeded in those intervals.

Expectedly, exposure loads received either before or after noon yield less erythemal dose than an interval of the same duration around noon for all considered UVI values. Also, due to the shift of our data to LST for normalization, intervals of equal length before and after noon lead to almost exactly equal doses. The shortest interval considered, $30 \mathrm{~min}$ around noon, does not yield doses exceeding MEDs of any skin type on any day. The $1 \mathrm{~h}$ interval around noon does so only for the MED of skin type I on $7.75 \%$ of UVI 2 days.

Median erythemal doses calculated for days with a UVI value of 0 are well below 1 SED for all intervals considered, except for doses for the total day. Still, even for this interval, the MEDs of skin types III and IV are never exceeded, and for skin types I and II in only $1.23 \%$ and $0.04 \%$ of days, respectively.

When median erythemal doses for UVI 1 days are considered, only the dose from a 4h-interval around noon and the full daily dose exceed MEDs of skin types I and I+II, respectively. Still, doses received during the $2 \mathrm{~h}$ and $3 \mathrm{~h}$ intervals around noon are greater than MEDs of the two sensitive skin types II, and especially I, for a considerable proportion (more than two thirds) of days.

Concerning UVI 2 days, some intervals, like $2 \mathrm{~h}$ around noon, pose serious risk of overexposure for skin type I, with nearly $90 \%$ of days giving doses exceeding MEDs for those intervals. In contrast, for skin type IV, the same intervals does not lead to the excess of 1 MED for any day in our sample. Erythemal doses from the $4 \mathrm{~h}$ interval around noon exceed MEDs of the melano-competent skin types III and IV in more than $80 \%$ and about one fourth of days, respectively. The full daily dose is greater than the MEDs of all Caucasian skin types for more than $90 \%$ of all UVI 2 days. 
Table 2. Ambient erythemal UV doses ( $\mathrm{Her}_{\mathrm{e}}$ calculated for different time intervals on days with a UVI value of 0,1 and 2. ( $1 \mathrm{SED}=1$ Standard Erythema Dose $=100 \mathrm{~J} / \mathrm{m}^{2}$ weighted with the CIE erythema reference action spectrum [6]).

\begin{tabular}{|c|c|c|c|c|c|}
\hline \multirow{2}{*}{$\begin{array}{c}\text { Time Interval (Local } \\
\text { Solar Time, } \\
\text { Duration) }\end{array}$} & \multirow{2}{*}{$\begin{array}{c}\text { Her (SED); Median (p10, } \\
\text { p90 Percentile) }\end{array}$} & \multicolumn{4}{|c|}{ MEDs Exceeded for ... \% of Days for Skin Type } \\
\hline & & I & II & III & IV \\
\hline \multicolumn{6}{|l|}{ Before noon } \\
\hline \multicolumn{6}{|l|}{ 8:00-10:00, 2 h } \\
\hline UVI 0 & $0.12(0.05,0.23)$ & 0 & 0 & 0 & 0 \\
\hline UVI 1 & $0.42(0.20,0.86)$ & 0.07 & 0 & 0 & 0 \\
\hline UVI 2 & $1.24(0.69,1.92)$ & 7.87 & 2.09 & 0 & 0 \\
\hline \multicolumn{6}{|l|}{$7: 30-10: 30,3 \mathrm{~h}$} \\
\hline UVI 0 & $0.19(0.09,0.36)$ & 0 & 0 & 0 & 0 \\
\hline UVI 1 & $0.67(0.34,1.31)$ & 1.03 & 0.15 & 0 & 0 \\
\hline UVI 2 & $1.90(1.11,2.85)$ & 44.32 & 19.92 & 0.89 & 0 \\
\hline \multicolumn{6}{|l|}{ Around noon } \\
\hline \multicolumn{6}{|l|}{$11: 45-12: 15,1 / 2 \mathrm{~h}$} \\
\hline UVI 0 & $0.11(0.05,0.19)$ & 0 & 0 & 0 & 0 \\
\hline UVI 1 & $0.32(0.20,0.54)$ & 0 & 0 & 0 & 0 \\
\hline UVI 2 & $0.74(0.43,1.00)$ & 0 & 0 & 0 & 0 \\
\hline \multicolumn{6}{|l|}{$11: 30-12: 30,1 \mathrm{~h}$} \\
\hline UVI 0 & $0.23(0.11,0.37)$ & 0 & 0 & 0 & 0 \\
\hline UVI 1 & $0.64(0.40,1.05)$ & 0 & 0 & 0 & 0 \\
\hline UVI 2 & $1.46(0.93,1.96)$ & 7.75 & 0 & 0 & 0 \\
\hline \multicolumn{6}{|l|}{$11: 00-13: 00,2 \mathrm{~h}$} \\
\hline UVI 0 & $0.44(0.21,0.70)$ & 0 & 0 & 0 & 0 \\
\hline UVI 1 & $1.24(0.80,2.03)$ & 10.99 & 0.49 & 0 & 0 \\
\hline UVI 2 & $2.83(1.92,3.80)$ & 87.89 & 68.65 & 5.37 & 0 \\
\hline \multicolumn{6}{|l|}{$10: 30-13: 30,3 \mathrm{~h}$} \\
\hline UVI 0 & $0.63(0.31,0.99)$ & 0 & 0 & 0 & 0 \\
\hline UVI 1 & $1.78(1.15,2.90)$ & 39.28 & 20.08 & 0 & 0 \\
\hline UVI 2 & $4.08(2.86,5.45)$ & 98.39 & 95.38 & 52.82 & 2.42 \\
\hline \multicolumn{6}{|l|}{ 10:00-14:00, $4 \mathrm{~h}$} \\
\hline UVI 0 & $0.79(0.39,1.23)$ & 0 & 0 & 0 & 0 \\
\hline UVI 1 & $2.24(1.43,3.64)$ & 60.72 & 39.82 & 4.51 & 0 \\
\hline UVI 2 & $5.14(3.71,6.88)$ & 99.79 & 99.14 & 84.01 & 26.39 \\
\hline \multicolumn{6}{|l|}{ After noon } \\
\hline \multicolumn{6}{|l|}{$14: 00-16: 00,2$ h } \\
\hline UVI 0 & $0.12(0.05,0.22)$ & 0 & 0 & 0 & 0 \\
\hline UVI 1 & $0.42(0.20,0.86)$ & 0.08 & 0 & 0 & 0 \\
\hline UVI 2 & $1.24(0.72,1.92)$ & 7.99 & 2.42 & 0 & 0 \\
\hline \multicolumn{6}{|l|}{$13: 30-16: 30,3 \mathrm{~h}$} \\
\hline UVI 0 & $0.19(0.08,0.36)$ & 0 & 0 & 0 & 0 \\
\hline UVI 1 & $0.67(0.33,1.32)$ & 1.32 & 0.25 & 0 & 0 \\
\hline UVI 2 & $1.92(1.16,2.85)$ & 44.68 & 20.34 & 0.95 & 0 \\
\hline \multicolumn{6}{|l|}{ Full day } \\
\hline \multicolumn{6}{|l|}{ Sunrise-Sunset } \\
\hline UVI 0 & $1.04(0.52,1.65)$ & 1.23 & 0.04 & 0 & 0 \\
\hline UVI 1 & $3.21(1.95,5.46)$ & 88.49 & 70.51 & 32.58 & 4.72 \\
\hline UVI 2 & $8.17(6.01,10.87)$ & 99.97 & 99.97 & 99.79 & 90.19 \\
\hline
\end{tabular}

\section{Discussion}

\subsection{Summary of Results}

Our analysis demonstrated that MEDs are exceeded on many days with UVI values of 2 (and under specific circumstances, also 1), after a few hours of outdoor exposure, especially for the fair 
skin types I and II. In contrast, MEDs are exceeded for just a negligibly small number of days with UVI 0 under extreme exposure conditions. UVI 0 days therefore do not seem to pose any risk of overexposure to UV radiation. Marked differences between skin types in terms of percentages of days for which one MED is exceeded for a given time interval have been illustrated in our analysis, reflecting known differences in susceptibility to UV damages between the four Caucasian skin types (Table 1).

\subsection{Possible Implications of Results}

Our analysis, an extension of a pilot study from 2017 [15], and recent evidence from New Zealand [16,17] imply that recommending sun protection on UVI 2 days for sensitive skin types should be discussed during a process of updating current public health messages connected to different UVI levels. In addition, the adaptation of UVI guidance to different skin types should also be considered. Up to now this has not been done, most probably because of the general notion to keep health messages to the public as simple as possible ('Keep It Simple, Stupid', KISS principle). Nevertheless, the complex situation in this case might justify the preparation of a 'matrix' of health messages for different skin types. Local health authorities could choose entries of the matrix suitable for the most sensitive major subgroup of a country or region. A similar solution, though resulting from an analysis primarily focusing on high instead of low UVI values, has been proposed by other authors already [18]. Both the necessity for local adaptation and the possibility of including skin type and exposure duration in the UVI guidance have already been ascertained at a WHO UVI workshop in Melbourne in 2015 [19]. Up until now, this has not been implemented. As a future perspective, smartphone applications could incorporate information on the individual skin phototype combined with calendar and geotagging data and possibly also UVI forecasting, to achieve highly individualised yet easy to handle information or alerts.

\subsection{Strengths and Limitations}

The strength of our analysis lies in the evaluation of a large dataset comprising measurement data of 10 consecutive years from 9 measuring stations of a solar UV monitoring network with a well-established system of quality control. In total, 14,431 daily UVI time series from the 'low' UVI category were available. Still, our study suffers from some limitations.

We used ambient erythemal irradiance data which are measured on horizontal detectors. Due to this the measurements are potentially weak proxies for individual exposure as most human skin surfaces are not oriented horizontally. On the one hand, surfaces facing the sun (almost) vertically can receive significantly higher irradiances (up to $40 \%$ ) during periods without cloud obstruction and with high SZA [20]. The majority of days in our sample (more than $90 \%$ of UVI 0 and 1 days and more than $60 \%$ of UVI 2 days) originate from the autumn and winter period and are therefore likely to represent this scenario. On the other hand, cloudy conditions can lead to UV on tilted surfaces being reduced by up to $50 \%$ in comparison to horizontal-incidence UV [20]. Cloudy conditions are likely to have been prevalent on many days in our sample during the late spring and summer period, because a thick cloud cover is needed to sufficiently attenuate UV radiation which would be much higher during cloudless days during this time of the year. Moreover, the ratio between personal and ambient exposure, frequently called exposure ratio (ER), is highly dependent on individual behaviour. This covers aspects like use of shade [21], intermittent indoor activities and body posture [22]. Values of ER for outdoor workers reported in a review from 2011 were 8-66\% (arms and wrists), 11-85\% (vertex) and 11-70\% (shoulders) [23]. Still, we think our study adequately represents a scenario of staying outside for prolonged periods on days with low UVI values, with no sun protection applied.

Furthermore, most of the days in our sample were in autumn and winter when people tend to cover most of their body in clothes due to low ambient temperatures. Still, the body parts that mostly remain uncovered are the hands and the face, which both are common localisations of skin malignancies [24] and are also oriented vertically while standing. This can, as discussed above, lead to even higher irradiances and doses because of the high SZA in this period of the year. 


\title{
5. Conclusions
}

WHO guidance for sun protection on days with 'low' UVI values needs reconsideration. Our analysis revealed that UV exposure for prolonged exposure durations on UVI 2 days and, under certain rare circumstances, even on UVI 1 days, reaches erythemal levels and thus sun protection is required to avoid deleterious effects. This particularly relates to sensitive skin types which might imply the need for skin type specific public health messages relating to the UVI.

Author Contributions: M.L., O.G. and W.U. developed the concept for the study. H.S. organized data provision from the German solar UV monitoring network and provided professional advice regarding technical aspects of spectroradiometer data. M.L. and O.G. defined the methodology for the data analysis. M.L. performed the data analysis. A.B.P. and O.G. supervised the data analysis. M.L. drafted the manuscript. A.B.P., H.S., W.U. and O.G. critically revised the draft manuscript for important intellectual content. M.L. holds responsibility for data curation of the study. O.G. is the guarantor of the study taking responsibility for the overall integrity of the manuscript.

Funding: This research was funded by the Friedrich-Alexander-Universität Erlangen-Nürnberg and received no external funding.

Acknowledgments: We would like to thank all institutions involved in the German Solar UV Monitoring Network for providing their data for this study. These institutions are: Federal Institute for Occupational Safety and Health (BAuA), German Federal Office for Radiation Protection (BfS), University of Kiel (CAU), German Weather Service (DWD), Labour Inspetorate of Lower Saxony (GAA-Ni), Bavarian Environmental Agency (LfU), German Federal Environmental Agency (UBA). Especially, we would like to thank Markus Wallasch (UBA) for his support in special aspects of data interpretation.

Conflicts of Interest: The authors declare no conflict of interest.

\author{
Abbreviations \\ The following abbreviations are used in this manuscript: \\ Eer: Erythemally weighted irradiance \\ Her: Erythemal dose \\ LST: Local Solar Time \\ MED: Minimal erythemal dose \\ SZA: Solar zenith angle \\ UV: Ultraviolet \\ UVI: Global Solar UV Index \\ WHO: World Health Oganization
}

\section{References}

1. International Agency for Research on Cancer. Iarc working group on the evaluation of carcinogenic risk to humans. Radiation. In IARC Monographs on the Evaluation of Carcinogenic Risks to Humans, no. 100d.; International Agency for Research on Cancer: Lyon, France, 2012.

2. Lucas, R.M.; McMichael, A.J.; Armstrong, B.K.; Smith, W.T. Estimating the global disease burden due to ultraviolet radiation exposure. Int. J. Epidemiol. 2008, 37, 654-667.

3. Erdmann, F.; Lortet-Tieulent, J.; Schuz, J.; Zeeb, H.; Greinert, R.; Breitbart, E.W.; Bray, F. International trends in the incidence of malignant melanoma 1953-2008--are recent generations at higher or lower risk? Int. J. Cancer 2013, 132, 385-400.

4. Leiter, U.; Eigentler, T.; Garbe, C. Epidemiology of skin cancer. Adv. Exp. Med. Biol. 2014, 810, 120-140.

5. International Commission on Non-Ionizing Radiation Protection. Global Solar UV Index-A Joint Recommendation of the WHO, WMO, UNEP and the ICNIRP; International Commission on Non-Ionizing Radiation Protection: Oberschleissheim, Germany, 1995.

6. Commission Internationale de l'Eclairage (CIE). Erythema reference action spectrum and standard erythema dose. In ISO 17166:1999(E) / CIE S 007/E-1998; CIE Central Bureau: Vienna, Austria, 1998.

7. World Health Organization (WHO). Global Solar UV Index: A Practical Guide; WHO: Geneva, Switzerland, 2002.

8. Sandmann, H. Das solare UV-Messnetz des BfS/UBA. StrahlenschutzPRAXIS 2015, 38-40. 
9. Schmalwieser, A.W.; Grobner, J.; Blumthaler, M.; Klotz, B.; De Backer, H.; Bolsee, D.; Werner, R.; Tomsic, D.; Metelka, L.; Eriksen, P.; et al. UV index monitoring in europe. Photochem. Photobiol. Sci. 2017, 16, 13491370.

10. Fitzpatrick, T.B. The validity and practicality of sun-reactive skin types I through VI. Arch. Dermatol. 1988, 124, 869-871.

11. Feister, U.; Laschewski, G.; Grewe, R.D. UV index forecasts and measurements of health-effective radiation. J. Photochem. Photobiol. B 2011, 102, 55-68.

12. R Core Team. R: A Language and Environment for Statistical Computing; R Foundation for Statistical Computing: Vienna, Austria, 2017.

13. International Commission on Non-Ionizing Radiation Protection. Protecting Workers from Ultraviolet Radiation; International Commission on Non-Ionizing Radiation Protection: Oberschleissheim, Germany 2007; p. 42.

14. Trenberth, K.E. What are the seasons. Bull. Am. Meteorol. Soc. 1983, 64, 1276-1282.

15. Lehmann, M.; Pfahlberg, A.B.; Sandmann, H.; Uter, W.; Gefeller, O. Implications of low levels of the UV index for sun protection. Stud. Health Technol. Inform. 2017, 243, 25-29.

16. Lucas, R.M.; Neale, R.E.; Madronich, S.; McKenzie, R.L. Are current guidelines for sun protection optimal for health? Exploring the evidence. Photochem. Photobiol. Sci. 2018, 17, 1956-1963.

17. McKenzie, R.L.; Lucas, R.M. Reassessing impacts of extended daily exposure to low level solar UV radiation. Sci. Rep. 2018, 8, 13805.

18. Zaratti, F.; Piacentini, R.D.; Guillen, H.A.; Cabrera, S.H.; Liley, J.B.; McKenzie, R.L. Proposal for a modification of the UVI risk scale. Photochem. Photobiol. Sci. 2014, 13, 980-985.

19. Gies, P.; van Deventer, E.; Green, A.C.; Sinclair, C.; Tinker, R. Review of the global solar UV index 2015 workshop report. Health Phys. 2018, 114, 84-90.

20. McKenzie, R.L.; Paulin, K.J.; Kotkamp, M. Erythemal UV irradiances at lauder, new zealand: Relationship between horizontal and normal incidence. Photochem. Photobiol. 1997, 66, 683-689.

21. Sandmann, H.; Stick, C. Spectral and spatial uv sky radiance measurements at a seaside resort under clear sky and slightly overcast conditions. Photochem. Photobiol. 2014, 90, 225-232.

22. Vernez, D.; Milon, A.; Vuilleumier, L.; Bulliard, J.L.; Koechlin, A.; Boniol, M.; Dore, J.F. A general model to predict individual exposure to solar UV by using ambient irradiance data. J. Expo. Sci. Environ. Epidemiol. 2015, 25, 113-118.

23. Siani, A.M.; Casale, G.R.; Sisto, R.; Colosimo, A.; Lang, C.A.; Kimlin, M.G. Occupational exposures to solar ultraviolet radiation of vineyard workers in Tuscany (Italy). Photochem. Photobiol. 2011, 87, 925-934.

24. Stanienda-Sokol, K.; Salwowska, N.; Slawinska, M.; Wicherska-Pawlowska, K.; Lorenc, A.; Wcislo-Dziadecka, D.; Wydmanski, J.; Majewski, W. Primary locations of malignant melanoma lesions depending on patients' gender and age. Asian Pac. J. Cancer Prev. 2017, 18, 3081-3086.

(C) 2018 by the authors; licensee MDPI, Basel, Switzerland. This article is an open access article distributed under the terms and conditions of the Creative Commons by Attribution (CC-BY) license (http://creativecommons.org/licenses/by/4.0/). 